\title{
EL CANTO Y LOS MAESTROS VARONES: UN ESTUDIO DE CASO EN UN COLEGIO PÚBLICO DE LA COMUNIDAD DE MADRID
}

\author{
Albina Cuadrado Fernández
}

Universidad Complutense de Madrid

alcuadra@edu.ucm.es

\begin{abstract}
Este trabajo surge de una preocupación derivada de mi práctica en la formación del profesorado. Tiene como fin averiguar la problemática que genera el proceso de enseñanza-aprendizaje del canto en un maestro varón dentro del ámbito de la enseñanza general. Pretende, además, ubicar y comprender dicha problemática en su contexto. No sólo viene a paliar la ausencia de investigación al respecto, sino también a abrir cauces para el desarrollo de didácticas específicas basadas en la investigación que puedan repercutir fructíferamente en las escuelas. Como estrategia de indagación utilicé el estudio de casos, empleando técnicas de recogida de datos asociadas con la metodología cualitativa. El análisis y la interpretación de los datos revelan que el perfil del maestro es determinante y que tiene gran incidencia en la práctica vocal de aula al poner de manifiesto las interacciones entre la formación vocal del maestro, el modelo vocal que ofrece y la práctica de aula. La cuestión de género plantea una problemática vocal específica con implicaciones relevantes. Además, de este estudio derivan sugerencias significativas relacionadas con la formación vocal de los maestros.
\end{abstract}

This investigation was motivated by concerns derived from my teaching training practice. It aimed at analyzing the specific problems faced by male music teachers in the vocal teaching and learning process in primary schools, and also at understanding those problems in context. The study tried to fill a lack of research on this issue, and also to pave the way for the development of specific teaching strategies that may render practical benefit for schools. Case study was used as strategy of enquiry, and data collection methods associated with qualitative methodology were followed. Data analysis and interpretation reveal that male teachers' profiles are crucial in a singing class and have a significant impact on the lesson, highlighting the interactions among the teacher's own vocal training, the vocal model he follows and his classroom practice. The question of gender poses a specific set of problematic vocal issues with strong implications. In addition, significant suggestions related to the vocal training of teachers are also derived.

El presente trabajo surge de una preocupación derivada de mi práctica docente como profesora de Formación Vocal en la Facultad de Educación de la Universidad Complutense de Madrid. Algunos de mis alumnos, futuros maestros especialistas en educación musical, manifiestan reticencias ante el canto y diversos problemas vocales. Necesitamos una didáctica basada en la investigación que ayude a comprender la problemática generada por la enseñanza y el aprendizaje del canto dentro de la enseñanza general.

Con este estudio se pretende averiguar la problemática específica que genera el proceso de enseñanza-aprendizaje del canto en un maestro varón y comprenderla en su contexto, tanto para paliar la ausencia de investigación al respecto, como para abrir cauces en el desarrollo de didácticas específicas que puedan repercutir fructíferamente en las escuelas. Para ello, se ha partido de una serie de interrogantes relacionados con la naturaleza de la práctica vocal, con el modelo de voz hablada y cantada que ofrece el maestro en el aula, con la posible existencia de interacciones entre formación vocal, modelo vocal y práctica de aula, con la percepción que de ello tiene el maestro y con la correspondencia entre percepciones y acciones docentes.

\section{METODOLOGÍA Y DISEÑO}

Sirviéndome de la metodología cualitativa utilicé, como estrategia de indagación, el estudio de casos, realizando lo que STAKE (1998:17) denomina un "estudio instrumental", ya que la elección del caso surgía frente a una cuestión general y respondía al interés por comprenderla. La organización de la recogida de datos obedeció a un plan fundamentado en las preguntas de la investigación, sobre la base de qué era lo que necesitaba saber y por qué, y de cuál era la mejor forma de recoger la información. Las técnicas de recogida de datos fueron las asociadas con la metodología cualitativa: la observación, la entrevista, las notas y diarios de campo, y el análisis de documentos y materiales. 
Para el presente trabajo utilicé la observación como primera técnica de recogida de información, que sirvió para obtener descripciones de cada situación. Realicé una observación directa, no participante y no estructurada aunque, en este sentido, suscribo el pensamiento de KUSHNER (2002) cuando, a propósito de sus observaciones, indica que todas ellas están "estructuradas" por el interés que él tiene en la interacción humana, sus propios valores y todo lo que eso lleva consigo. Las observaciones se efectuaron en el aula de música durante las sesiones impartidas por el maestro especialista en Educación Musical en todos y cada uno de los seis cursos que constituyen la etapa de Educación Primaria. Recogí los datos de forma sistemática, minuciosa y exhaustiva mediante el registro anecdótico.

Utilicé la entrevista como segunda técnica de recogida de datos, en sus variantes abierta y semiestructurada, planificada y espontánea, y formal e informal. Como recurso tecnológico me serví, básicamente, de una grabadora digital cuyo contenido podía ser transvasado al ordenador, facilitando de esta forma la transcripción de los datos. En las ocasiones en que se trataba de una entrevista espontánea o informal recurrí al registro escrito inmediato. Realicé las transcripciones tan pronto como me fue posible para no distanciarlas de la sesión en la que había tenido lugar la entrevista, estableciendo como criterio principal que entre las sucesivas sesiones hubiese un intervalo de tiempo suficiente que me permitiese analizarlas adecuadamente.

En tercer lugar, las notas y diarios de campo resultaron de gran utilidad para mi trabajo, aportando detalles de gran sutileza, sirviéndome como herramientas para la reflexión y para la triangulación. Por último, analicé documentos tales como artículos, informes, actas, textos oficiales, horarios, vídeos, grabaciones, programaciones, tableros de anuncios, exposiciones y murales.

Este trabajo forma parte de una investigación más amplia: un estudio colectivo de casos que tuvo lugar en el contexto general de los centros de educación primaria de la Comunidad de Madrid, donde se desarrollaba la actividad docente de los maestros especialistas en Educación Musical que, en su momento, participaron en la investigación. Previo a la elección de los participantes establecí determinados criterios sobre cuales iban a ser los posibles casos susceptibles de llevar a la comprensión de aquello que pretendía estudiar, siguiendo el principio de máxima variación descrito por LINCOLN y GUBA (1985), que atiende a la diversidad de los participantes y de los centros donde iba a tener lugar la investigación tal como preconiza STAKE (1998) cuando sugiere la elección de un conjunto de casos equilibrado y variado. De este modo, tuve en cuenta tanto la edad, el género, la formación y el perfil vocal de los participantes, como la tipología y la ubicación de los centros. Para obrar en consecuencia con el mencionado "principio", solicité la participación en la investigación de un maestro varón especialista en Educación Musical que era cantautor y compositor, y cuya edad se situaba en torno a la cincuentena, que enseñaba en un colegio público ubicado en una localidad cercana a Madrid. El maestro no sólo ofreció disponibilidad y brindó todo tipo de facilidades, sino que incluso acogió con agrado la propuesta de participar en la investigación. El acceso al contexto resultó libre de obstáculos, y, en el proceso de negociación de dicho acceso, sólo se me requirió expresamente por parte de la dirección del centro que no utilizase grabaciones de vídeo en las sesiones de observación. Por mi parte, asumí por escrito una serie de compromisos previos que salvaguardaban el anonimato, tanto del colegio como del maestro -de ahí el uso de seudónimos-, y que garantizaban la ausencia de interferencias en el funcionamiento del centro y de cualquier acción unilateral por mi parte sin el consentimiento de los involucrados.

El trabajo de campo tuvo lugar durante el curso 2007-2008. Una vez realizada la transcripción de los datos, el corpus documental quedó constituido por un total de 11 documentos primarios. El análisis e interpretación de los datos es un proceso cíclico y recurrente que resulta complejo y laborioso por su carácter emergente (PESHKIN, 2000). Si bien es cierto que cuando se registra y describe ya se interpreta y se categoriza la realidad de alguna manera, cuando se trabaja con textos, la primera fase de análisis consiste en identificar segmentos significativos para la investigación a los que se les asigna un código en base a unos criterios temáticos (SALDAÑA, 2009). Codificar es un 
proceso que busca ir más allá de los datos pensando de forma creativa con ellos, formulándoles preguntas y generando teorías y marcos conceptuales para convertir los datos "codificados" en datos "significativos" (COFFEY y ATKINSON, 2005). La codificación, pues, no es una actividad mecánica ni sencilla. Para este propósito recurrí al programa informático Atlas.ti, que está especialmente diseñado para estimular al investigador a ir más allá de emprender la fragmentación y codificación de los datos, animando al analista a construir relaciones sistemáticas entre las categorías de códigos, y de estos códigos con otros elementos tales como los fragmentos de datos originales o los "memos" -comentarios reflexivos de carácter analítico, metodológico, teórico o de cualquier otra naturaleza que necesita realizar el investigador a lo largo del proceso-, a los que la literatura otorga una gran relevancia. Para CORBIN y STRAUSS (1990), los memos analíticos no son simplemente ideas, sino que están involucrados en la formulación y revisión de la teoría y aportan una base firme para elaborar el informe investigación y sus implicaciones. El programa informático resultó ser de gran utilidad a la hora de realizar tareas de manejo, recuperación y análisis de los datos, y también en tanto que mecanismo heurístico para explorar las relaciones entre categorías y conceptos, ya que éstas podían visualizarse y modificarse.

En la investigación cualitativa, el investigador, en la búsqueda de precisión y de explicaciones alternativas, necesita disciplina y estrategias que no dependan de la simple intuición y de las "buenas intenciones". Estas estrategias se llevan a cabo mediante un procedimiento conocido como "triangulación", que sirve para dar interpretaciones lo más acertadas posibles y obtener credibilidad. La triangulación es un proceso mediante el cual el investigador huye de cualquier interpretación superficial para ir a la búsqueda de múltiples y variados significados obligándose a la revisión sistemática. Entre las diferentes opciones que existen, utilicé la triangulación de técnicas de recogida de datos que, según STAKE (1998:99), resulta ser la estrategia más aceptada e incluye fundamentalmente la observación, la entrevista y la revisión de documentos para poder ver aquello que no "habíamos percibido", o, al menos, no de la misma manera.

La investigación cualitativa no es unidireccional ni estática, y deja siempre espacio para el debate y la diferencia. Tiene un ritmo no predecible, aunque no por ello haga apología de planteamientos ilusionados o descuidados. Los sellos del método cualitativo son, para EISNER (1998), la flexibilidad, el ajuste y la interacción. Así pues, el diseño de la investigación cualitativa es emergente a pesar de estar planificado, está siempre pendiente de confirmación y se va focalizando progresivamente.

\section{LA INVESTIGACIÓN}

\section{El maestro}

Cantautor, compositor y poeta, Aitor se recordaba a sí mismo cantando desde la infancia. Su experiencia en el conservatorio se vio interrumpida en determinados momentos, resultando dilatada en el tiempo. Obtuvo el grado elemental de canto. Había desarrollado también con la guitarra la habilidad necesaria como para poder acompañarse y componer. Su interés por formarse como cantante le llevó a intentar ingresar en la Escuela Superior de Canto. La experiencia de no superar la prueba de acceso y no haber podido acceder a esa formación le supuso frustración. Para Aitor este episodio y sus consecuencias seguían constituyendo objeto de reflexión y de pesadumbre. Echaba en falta alguna figura que, ejerciendo en él como mentor, le hubiera podido asesorar con el repertorio que debía presentar para la prueba y que, de alguna manera, hubiese representado aliento y apoyo en su carrera. Su discurso latente dejaba entrever la ausencia de un entorno favorecedor de su crecimiento y de sus inquietudes como cantante y como músico.

-Por eso no seguí, aunque mi intención hubiera sido... De hecho lo intenté en la Escuela de Canto y no aprobé. No supe qué había que presentar en ese tipo de escuela... Si me hubieran contado en el camino, o si me hubiera encontrado con alguna persona coherente, seguramente habría luchado por terminar la carrera de canto clásico, porque era una cosa que me atraía. Aunque ahora seguramente estaría donde estoy, pero eso que me habría llevado en la mochila. 
El rasgo más relevante durante su etapa de formación fue el dilema en que se encontraba a la hora de compaginar sus estudios musicales con el bachillerato en un primer momento, y con los estudios de magisterio más adelante. Las múltiples idas y venidas al conservatorio dieron lugar a una alternancia no siempre equilibrada, que provocó una vivencia dual ante la inquietud por formarse musicalmente y, a la vez, no descuidar la otra formación, lo que le llevó, en ocasiones, a priorizar una en detrimento de la otra.

Esta inquietud, así como el hecho de no haber encontrado un lugar en el sistema educativo musical convencional, le llevaron a buscar vías alternativas -escuelas de música con enseñanza reglada, profesores particulares o la práctica musical con colegas de música ligera experimentados-, que resultaron relevantes para su formación musical. En estos contextos de aprendizaje más o menos informales se sentía cómodo, incentivado y, aún con el paso del tiempo, seguía considerando que habían resultado cruciales tanto para su evolución musical como para afianzarse en la decisión, en un momento dado, de ser un profesional de la música como intérprete.

El dilema que vivía el joven que se estaba formando no desapareció al comenzar la vida profesional. Muy al contrario, se acrecentó, haciéndose más profundo. La necesidad de expresarse, de hacer música y el querer hacer de ello su profesión, no siempre le proporcionaron estabilidad económica, por lo que volvió a vivir esa alternancia periódica, aunque ahora ya como docente o profesional de la música.

\begin{abstract}
-Compaginaba con la música lo que podía. Al final dejé una temporada la música y me dediqué a terminar. Cuando terminé, volví al conservatorio. Al conservatorio me fui y me vine como tres veces, hasta que por fin acabé todo el grado elemental. Y desde que tuve esa visión del mundo educativo alterné la música en directo en el mundo profesional con la enseñanza, y pasé temporadas. Nada más terminar estuve sólo en la enseñanza, pero a los tres o cuatro años tomé la decisión de retomar los estudios en el conservatorio y los de música alternativa, con armonía y demás. Ahí fue quizá donde más aprendí. Yo era una persona con veinte y muchos que sabía muy bien lo que quería. Ahí tomé la decisión importante de convertirme en un profesional de la música, o por lo menos de intentarlo. Otra cosa es que las cosas luego no vengan como uno quiere. Abandoné un poquito todo lo que es el magisterio durante una temporada larga de siete u ocho años en los que la actividad educativa la mantenía a nivel particular. Daba clases en pequeños grupos de infantil en mi casa con lo que surgía de la nueva creación. Lo que ahora tienen con los críos, pues que te juntabas con ellos en una alfombra, instrumentos y tal, y experimenté ahí. Tuve mucha suerte, porque la escuela infantil donde yo venía de trabajar, pues los padres [de los niños a los que enseñaba en ese centro] me trajeron a los críos [a su propio domicilio para que pudiesen seguir trabajando con él] y creo que hay chavales que ahora son músicos, lo cual para mí es un orgullo.
\end{abstract}

Pasado un tiempo, abandonó el proyecto vital por el que tanto había luchado y apostado. Volvió a la enseñanza por necesidad y dio prioridad a la docencia frente al ejercicio de su profesión como intérprete. Sus actitudes vitales revelaban gran inquietud, sensibilidad, búsqueda incesante y, sobre todo, una ineludible necesidad de expresarse haciendo música, fundamentalmente cantando. Era consecuente con una impronta generacional que impregnaba su manera de enfrentarse al mundo y que tenía relación con el hecho haber nacido en España en la década de 1950 en un régimen no democrático donde los derechos individuales y colectivos eran una aspiración a conseguir.

Vivió la "movida madrileña" en primer plano. Ese movimiento contracultural surgido durante los primeros años de la transición de la España posfranquista con la connivencia y el apoyo de determinados dirigentes políticos en un afán de mostrar un punto de inflexión entre la sociedad franquista y la nueva sociedad de la democracia, se prolongó hasta finales la década de 1980 e hizo de la música una de sus manifestaciones más genuinas. En ese ambiente, Aitor participó de una estética, una mentalidad y, sobre todo, de una práctica musical en la que confluían y se acrisolaban diferentes estilos: rock, pop, jazz y músicas étnicas, entre otros. Paralelamente, se sintió interesado en el teatro, cuya experiencia se había vuelto imprescindible para él.

Entre los rasgos que configuraban su perfil destacaba el hecho de que era un maestro entusiasta, entregado, con carisma y que, además, gozaba de gran ascendente sobre sus alumnos. El pensamiento docente de Aitor se articulaba a partir de su formación, de su perfil y de las reflexiones 
a propósito del contexto en el que desarrollaba su práctica docente, fundamentalmente sobre los imperativos que provenían del ámbito de la educación general. Era muy crítico con la educación que había recibido en su infancia y también tenía muchas dudas con respecto a la educación actual. Cuestionaba los valores culturales y sociales dominantes y el papel de la familia actual en términos educativos. Defendía el papel del maestro como educador y no como mero transmisor de conocimientos. Tenía una visión democrática de la educación, y estaba convencido del valor de la educación en tanto que agente y motor de cambio social. Tenía gran conciencia social. Le preocupaban algunos niños que sentía que estaban "como abandonados", e intentaba rescatar a aquellos que abandonaban los estudios.

El canto era un tema omnipresente en su discurso, pero no desde el punto de vista del didacta, sino a propósito de sí mismo, como el cantante que era, el cantante que le hubiese gustado llegar a ser, las influencias que había recibido o la ductilidad vocal que se atribuía. La necesidad de imágenes referenciales por parte del maestro se dirigía a la búsqueda de un estilo vocal propio, lo que hacía extensivo a cualquiera que pudiera encontrase en ese proceso. Se enorgullecía cuando terceras personas identificaban las influencias estilísticas que había recibido y se sentía de alguna manera heredero de esas figuras a las que admiraba y que, además, le habían servido como referente vocal.

-He pasado diferentes etapas. Cuando yo estaba en el conservatorio tenía una obsesión, un cuidado. Cuidaba todo el cuerpo. Estaba pendiente. "No tengo que entrar en sitios que no sé qué", "no...". O sea, un rollo [...]. Pero bueno, era una etapa en la que yo quería ser cantante lírico y estaba ahí en esa lucha. Y entonces me mantuve ahí un tiempo. Luego ya cuando pasé al jazz, mi obsesión era encontrar un timbre de voz, un estilo personal. Ya componía. Era buscar, eso me ha costado un tiempo. Siempre he tenido muchas comparativas: que si en algunas cosa me parecía a Hilario Camacho, que en otras al Gurruchaga, que si a Miguel Ríos... Siempre la gente busca una referencia, ¿no? Yo tengo todas las influencias y además me encanta tenerlas [...]. Creo que he nacido con una voz o con un físico para poder desarrollar muchos campos con la voz. Diferentes campos. Y además me divierte el poder tocar varios palos, varios estilos. Eso lo utilizo en mi música personal, lo utilizo con ellos. Yo creo que es riqueza, en general.

Reflexionaba sobre lo que significaba el hecho de cantar para él y manifestaba con claridad y realismo su propio perfil canoro. Se refería metafóricamente a la ópera, tanto para poner de manifiesto qué tipo de cantante no era, como para ubicar el canto en sus distintos ciclos vitales. Así como en su juventud había perdido la oportunidad de adquirir una formación como cantante clásico, y eso era algo que, en su madurez, escapaba a sus posibilidades, cuando pensaba en la etapa que vendría después de su vida activa como docente, lo contemplaba como un ideal, aunque inalcanzable, inexorablemente objeto de sus aspiraciones.

-Para mí, la voz es mi alma, lo que más domino -dentro de mi gremio, lógicamente. No me pongas a cantar ópera ahora porque, aunque me hubiera gustado en su momento, ahora ya no tengo el fuelle ni la fuerza. No sé si me diera cuando me jubile, no lo sé.

Entendía que su salud vocal, aunque un poco mermada, y salvo episodios puntuales, se mantenía aceptablemente a lo largo del tiempo. En tanto que docente, era consciente de pertenecer a un colectivo de riesgo debido a la sobreutilización de la voz como usuario de la voz profesional. En la percepción que tenía de su voz, detectaba determinados síntomas que se concretaban en fatiga vocal, pérdida de agudos, o cierta rasposidad en la voz. Sus síntomas coinciden con los que refiere ESCALONA (2006), cuando analiza las alteraciones más frecuentes de la voz en los docentes de primaria. El índice GRABS, propuesto por HIRANO (1981), sirve para analizar una serie de características tales como la rugosidad o rasposidad, así como la presencia de aire en la voz y la tensión al hablar o al cantar, y permite convertir en cuantitativo un parámetro cualitativo para poder compararlo. El profesor de canto, el otorrinolaringólogo o cualquier oído entrenado -incluido el propio interesado, como es el caso- son capaces de detectar auditivamente estas cualidades acústicas al escuchar una voz. La existencia de una alteración de una o más de las características acústicas de la voz -timbre, altura e intensidad- es lo que en la bibliografá especializada se conoce como "disfonía" (CASADO y PÉREZ, 2009). El maestro detectaba esas alteraciones, pero no había procurado apoyo profesional para solucionarlas. RUSSELL, OATES y GREENWOOK (1998) explican 
este fenómeno subrayando el hecho de que los maestros entienden los problemas vocales como "gajes del oficio" o "daños colaterales" y pueden no tener conciencia de la necesidad de solicitar ayuda para resolverlos. Aitor era consciente de la existencia de determinados factores de riesgo y tomaba en cuenta algunas pautas de conducta relacionadas con la higiene vocal como la hidratación -cuya ausencia puede incrementar el esfuerzo vocal y va en detrimento de la fisiología de las cuerdas vocales (SIVASANKAR y LEYDON, 2010).

Aitor consideraba el incremento de la intensidad al hablar como un importante factor de riesgo e identificaba en su práctica docente algunos comportamientos fonotraumáticos como el grito, procedimiento que encontraba prácticamente ineludible en la enseñanza primaria. La disminución de comportamientos fonotraumáticos tales como el carraspeo, el uso de la voz fuerte, el grito o el chillido, el hablar por encima del entorno ruidoso o una producción de la voz no convencional, según BEHLAU y OLIVEIRA (2009), son recomendaciones incluidas en la mayoría de los programas de higiene vocal. Además, el hablar muy fuerte durante largos periodos, según CHEN y sus colaboradores (2010), puede aumentar el cierre de la glotis y producir tensión e impacto sobre las cuerdas vocales, causando problemas funcionales en la voz y nódulos en las cuerdas vocales. La probabilidad de desarrollar un desorden vocal aumenta cuando se habla con una gran intensidad. Esto puede deberse a la reverberación en las aulas, que provoca un alto nivel ambiental de ruido e incita a los maestros a aumentar la intensidad al hablar para poder ser escuchados. Los especialistas están de acuerdo en la necesidad de reducir no sólo la intensidad, sino también la cantidad de tiempo en el empleo de la voz para paliar los efectos de una excesiva demanda vocal (BEHLAU y OLIVEIRA, 2009). Aitor apreciaba los beneficios que representaba para su voz la disminución de la actividad vocal en los periodos vacacionales sin docencia.

La influencia de determinados patrones estéticos que provenían del contexto de la música ligera y del jazz le había llevado a hacer gala de esa rasposidad que alteraba el timbre de su emisión, de modo que reivindicaba y convertía en categoría estética síntomas de posible falta de salud vocal, e incluso, patologías severas diagnosticadas.

\begin{abstract}
-En el primer disco que saqué en el 2000 tuve una... -claro, estaba trabajando y un mes antes me dio una afonía. Yo creo que fue absolutamente nervioso, pero tuve que tomar corticoides para poder recuperar. Yo no sé si estaba bloqueado. Entre que la autoestima siempre ha sido baja y era un reto personal, que quería que saliera bien [...]. Ponía todo mi empeño [...]. Pero yo estoy contento. Dentro del trabajo que supone estar dando clase a más de 470 alumnos, mi voz se conserva estupendamente. Sí es cierto que cada vez que llegan las vacaciones, a los diez o doce días, mi voz vuelve a tener la tímbrica un poquito más aguda. Al principio, cuando volví a la enseñanza lo pasé muy mal porque sabía que iba a sufrir con la voz, pero luego vas cogiendo un ritmo, que paras, que si bebes agua. Consigues una serie de hábitos que te permiten matizar, no hacerte tanto daño, para poder llegar por la tarde a tu casa y cantar lo que te apetece. Lógicamente, se pierde. Además, aquí estás hablando y de repente tienes que pegar un grito. Eso quiere decir que las cuerdas vocales están sufriendo un choque gordo. Pero, bueno, también le he pillado el punto. A veces salen composiciones gracias a esa tímbrica que ha bajado sin querer y que tiene ahí ese puntito con un poquito de migaja en las cuerdas vocales. Es un placer, ¿no? El señor Camarón de la Isla tenía siete pólipos en las cuerdas vocales y creo que Montserrat Caballé tiene o ha tenido dos en su vida. ¡Ésos son timbres! ¡No pasa nada!
\end{abstract}

El eje central de su pensamiento se articulaba en la forma en que había vivido la dualidad en tanto docente y profesional de la música. Sus circunstancias personales y vitales no le habían permitido contemplar esta dualidad como una opción con facetas complementarias, aunque lo fuesen de facto, sino como opciones excluyentes que había ido alternando por imperativos de supervivencia. De la génesis y posterior gestión de estas alternancias emergía un conflicto aún no resuelto que teñía su discurso de cierta frustración.

- Creo que como nos ha pasado a cualquier creativo dentro del mundo de la música. Triunfan un tres por
ciento, de todos los que nos dedicamos a la enseñanza, que valemos lo mismo que ellos. Y que no hemos
podido desarrollar... A lo mejor si hubiéramos tenido la posibilidad económica -porque realmente todo se
resume en eso- de desarrollar determinadas cosas, determinados retos, habríamos evolucionado de otra
manera [...]. Yo si hubiera estudiado el grado medio y el grado superior -que me hubiera encantado, la
verdad, me hubiera encantado [...]. Es evidente que la persona que tiene la posibilidad de estar sólo a sí 
mismo, cuidándose la voz, y desarrollando lo que ha querido desarrollar, es una persona más privilegiada que yo, es evidente. A mí me gusta la enseñanza, pero si yo tuviera en algún momento de mi vida la posibilidad de tirarme unos años en años que me fuera bien económicamente y poder seguir creando canciones y tocando en directo, y desarrollando, investigando... pues sería una gozada. Es otra faceta de mi vida que me hubiera encantado desarrollar. No estoy mal, pero la saturación o la monotonía es algo que es bonita cuando tú la eliges. ¡Es lo que hay! Y es mejor levantarse con una sonrisa que estar ahí todo el día... Aunque hay momentos que se hacen duros, la verdad.

\section{En el aula}

Según BRESLER (2004:1), para comprender la música escolar es necesario profundizar en los contextos que la "determinan y definen" interactuando entre sí: el "macro contexto", para los valores de la cultura de la sociedad; el "meso contexto", para las estructuras y fines del sistema escolar; y el "micro contexto" en cuanto a las intenciones y experiencia de los maestros. Apoyándome en esta distinción conceptual, observé que las interacciones entre el "micro" y "meso contexto" se caracterizaban por la fluidez y ausencia de conflictos. El colegio en el que Aitor trabajaba tenía tres grupos por cada uno de los seis cursos de educación primaria, con un alumnado de familias de clase media. El maestro se sentía cómodo y era muy valorado por sus compañeros. Las reflexiones a propósito de los imperativos que provenían del "macro contexto", no sólo configuraban el pensamiento del maestro, sino que encauzaban líneas prioritarias de actuación docente.

La práctica docente venía determinada por el uso de un libro de texto. Aitor comenzó a enseñar sin seguir texto alguno, pero con el tiempo ese trabajo le resultó agotador. Probó con algunos libros de los que tomaba ideas, sin utilizarlos de forma sistemática, hasta que unos músicos compañeros suyos editaron uno que le convenció, y que era el que utilizaba en aquel momento. Su didáctica se dejaba llevar por un libro de texto que propiciaba determinadas dinámicas y estrategias con menoscabo de otras. Ese libro de texto proponía unos materiales que, por su condición y por la utilización que de ellos se hacía, no favorecían el desarrollo del conocimiento procedimental, que en música implica poder cantar o tocar, discriminar auditivamente y crear música más que hablar sobre ella (RUSINEK, 2004). La disposición del aula de música era convencional, con pupitres colocados en filas. Solamente había un pequeño espacio diáfano en torno a la mesa del maestro y del equipo de grabación. Esta disposición del espacio impedía su utilización para el movimiento, imposibilitaba el trabajo con instrumentos escolares exceptuando la flauta dulce, y dificultaba el ejercicio del canto, que se realizaba en su mayor parte en posición sedente. Sin embargo, independientemente de los materiales y la organización del aula, la labor del maestro decididamente favorecía en los alumnos una actitud proclive hacia la música y la cultura. Los niños cantaban, tocaban la flauta o grababan en clase y, por encima de todo, disfrutaban. En quinto y sexto, dentro de un proyecto de innovación pedagógica, los alumnos creaban y diseñaban el guión para un cuento en pequeños grupos durante meses. Durante el proceso, confeccionaban diferentes fichas técnicas según las necesidades del guión, como, por ejemplo, la música o los efectos especiales que querían incluir. Trabajaban sobre los personajes y, finalmente, grababan.

Aitor empleaba un lenguaje muy campechano con los niños y les instaba al esfuerzo y a la reflexión. Era extremadamente meticuloso cuando corregía determinados aspectos de la voz hablada como son la dicción, la articulación, el fraseo, la intensidad o la ductilidad para recrear un personaje, pero no corregía la emisión ni utilizaba estrategias para mejorarla. Cuando realizaba estas correcciones conseguía resultados inmediatos y ostensibles.

\footnotetext{
- ¡Silencio, se graba! -dice dirigiéndose al pequeño grupo de alumnos que permanecen de pie, expectantes, muy cerca del equipo de grabación. -iLéelo como un narrador! -exclama dirigiéndose al niño que acaba de leer el primer fragmento. -Tienes que darle emoción desde el principio.

-Ese "por qué" está con mayúscula -vuelve a interrumpir para indicar que debe enfatizarlo aún más.

-Esto no lo habéis corregido - dice dirigiéndose al grupo mientras señala físicamente el guión. -¡Esto es con hache! -les indica.

-Tienes que decirlo de otra forma -corrige al niño que interpreta uno de los personajes. -iQue estás
} 
castigado! ¡Que estás mosqueado! ¿No eras un macarrilla? -dándole pautas sobre el carácter del personaje. - ¡No te rías, porque si no, no grabas! -dice amonestándole al ver que ante las correcciones, el niño reacciona con hilaridad. -¡Tienes que hacerlo más grave!

PHILliPs (1992) incide en que el canto es un comportamiento aprendido que va más allá de cantar canciones y que puede mejorarse con instrucción vocal. La práctica vocal en el aula distaba mucho de esta idea. De hecho, el maestro no contemplaba ese tipo de instrucción como requisito indispensable para el adecuado progreso de los alumnos en el ejercicio del canto y se limitaba a cantar las canciones del libro de texto. No había referencia práctica alguna para mejorar el proceso de coordinación en la producción vocal, y no tenía en cuenta que este proceso psicomotor complejísimo no ocurre espontáneamente en la mayoría de los niños -como señala PHILLIPS (1996) - y que éstos habrían necesitado un trabajo específico que lo articulase en relación a todos y cada uno de los parámetros psicológicos y fisiológicos que le son inherentes.

Había, en cambio, alguna referencia teórica puntual que reflejaba la ausencia de una experiencia vicaria en canto por parte del maestro, cuando se limitaba a exhortar, por ejemplo, a que "sacasen la voz", sin proporcionar las estrategias adecuadas para conseguirlo. Este tipo de exhortaciones o explicaciones adlátere, podían perturbar y confundir a los niños porque no eran imágenes adecuadas a su nivel de madurez y porque a menudo les llegaban a través de una terminología canora equívoca $\mathrm{y}$, a veces, substancialmente errónea. La cultura oral que domina la enseñanza del canto a veces no concuerda con la ciencia del canto. Como señalan WELCH y sus colaboradores (2006), la naturaleza del vocabulario pedagógico del profesor de canto puede resultar, cuando menos, confusa. Aitor se había impregnado de ese vocabulario. Debido a que la mecánica del canto es interna, intangible y difícil de mostrar, en el proceso de enseñanza-aprendizaje del mismo se recurre, más aún que en otros instrumentos, a la figuratividad, utilizando imágenes como formas icónicas de representación de lo abstracto y sirviendo como lugar de conexión entre el significado y la experiencia sensible MAUDUIT (2005).

El canto de los niños ponía de manifiesto una problemática vocal relevante y diversa. Había niños que desafinaban. Algunos cantaban la melodía, pero fluctuando tonalmente hasta encontrar una zona más adecuada a su tesitura, o directamente cantaban más grave cuando les resulta muy agudo el repertorio. Los había que cantaban en otra tonalidad o cantaban otra melodía. Otros recitaban cuando querían cantar o ronroneaban en una especie de rezo o parlato. Muchos, niños y niñas, cantaban en octava grave directamente y, en algunos casos, oscilaban en la melodía buscando su octava, ante la dificultad que suponía para ellos emitir en esa zona, mientras que alguno se mantenía todo el tiempo en octava grave, sin oscilar. Había niños que no cantaban. Cuando cantaban en grupo, se producían extrañas heterofonías. Muy pocas veces cantaban en su octava. Muy pocas veces cantaban afinados.

-En esta canción voy a poner nota en canto fundamentalmente. ¡Poned alma! Alguno va a salvarse con esta canción -les dice. Comienzan a cantar todos juntos. La mayoría canta en octava grave. Algunas niñas lo hacen en su lugar. Se escuchan algunos ronroneos.

-Mantened el aire hasta el final. ¡Atención, os dejo solos! -les dice. - ¡Si os equivocáis, echadle gracia! ¡Subir el volumen en A! -les va indicando. - ¡Vais muy bien! ¡Es fácil! ¿No?

A continuación se alternan chicos y chicas para las estrofas, y cantan todos juntos el estribillo. Abandonan sus pupitres y se colocan de pie: los chicos a su izquierda y las chicas a su derecha.

-¡Estáis cantando para mí! -les dice. Comienzan a cantar de manera que se van alternando los solistas. Intervienen de dos en dos en las diferentes estrofas. El niño 1 y la niña 1 cantan en su octava, pero el niño 2 y la niña 2 ronronean. En la siguiente estrofa el niño 1 pierde el tono y acaba rezando la letra. En la tercera estrofa el niño 1 canta otra melodía, y en la cuarta también el niño 2 canta otra melodía. Las niñas 1 y 2 terminan recitando.

-¡Sacad la voz fuera! ¡Hay que subir, eh! -les dice, pero continúan cantando igual. -¡Os habéis dejado influir! ¡Tenéis que subir! ¡Ahora vosotras! -les va indicando, pero tampoco corrigen.

-iHay que cantar para afuera, no para adentro! -les exhorta finalmente. 
El canto en el aula se caracterizaba por la ausencia de instrucción vocal. Se ceñía a cantar canciones y sólo se usaba como recurso para algunos aprendizajes musicales, fundamentalmente la lectura, o como ayuda para solucionar los problemas en la ejecución instrumental de la flauta.

El maestro seguía un libro de texto que proponía un repertorio complicado, de ámbito amplio, interválica difícil, textos muy extensos y arreglos de dudosa idoneidad para la etapa. Con respecto a este repertorio, no hacía ningún tipo de filtro. La mayoría de las canciones, o los fragmentos que entonaban del repertorio para flauta, se movían en el ámbito de octava, e incluso novena, independientemente del curso o ciclo, lo cual generaba una problemática insoluble con respecto a los agudos, pues la mayoría de los niños, independientemente del nivel y salvo que estén entrenados, empiezan a tener dificultades para entonar a partir del $\mathrm{la}^{4}$. En esta circunstancia podría estar el origen de algunas de las desafinaciones, oscilaciones, fluctuaciones tonales o el cambio de octava. Una interválica complicada, de terceras o cuartas ascendentes o descendentes, puede incrementar, también, las dificultades en la entonación en niños pequeños, o no entrenados. Además, canciones muy extensas con melodías y textos versionados del repertorio que formaba parte del corpus de canciones colectivo que seguía vigente en la memoria de los niños, o propuestas a dos voces en primer curso, incrementaban las dificultades a la hora de cantar.

El modelo vocal se contempla como un parámetro que afecta a la percepción tonal y, por lo tanto, a la afinación y a la calidad vocal debido a la relación que existe entre percepción y producción de los sonidos. Los niños tienen más facilidad para percibir el tono afinadamente si el modelo que escuchan es presentado adecuadamente afinado y se produce en su propio ámbito. El modelo masculino, en cuanto que suena una octava por debajo, resultaría especialmente problemático para niños que no tienen experiencia como cantantes, mientras que el modelo femenino, siempre que sea correcto, sería más favorable para ello, como lo es también la voz de los propios niños. Los niños pueden acceder mejor al tono y afinar mejor si el profesor varón les propone el modelo en falsete, lo que sugiere que los varones que trabajan cantando con niños necesitan desarrollar la habilidad de cantar una octava por encima para no confundir en la percepción del tono (PHILLIPS, 1992; 1996).

GREEN (1990), profundiza en la idea de que el modelo vocal tiene un efecto a la hora de encontrar el tono exacto. Utiliza un modelo vocal adulto masculino, otro modelo adulto femenino y modelos de niños, y encuentra más respuestas correctas al modelo de los chicos, seguido por el femenino y, en último lugar, el masculino. YARBROUGH y sus colaboradores (1991) hallan diferencias significativas entre la respuesta frente a los modelos masculinos y femeninos, con muchas más respuestas correctas con respecto al femenino. YARBROUGH, BOWERS y BENSON (1992) estudian el efecto en la afinación frente a modelos vocales cantando con y sin vibrato en cantantes "seguros" e "inseguros". Los cantantes "seguros" producen un alto porcentaje de respuestas correctas independientemente del sexo, grado o el modelo presentado. En contraste, los cantantes "inseguros" responden más correctamente al modelo sin vibrato. En la búsqueda de estrategias para encontrar la afinación en chicos versus chicas que desafinan, PRICE y sus colaboradores (1994), encuentran que las respuestas al estímulo masculino, ya sea en falsete o en su octava, fueron más afinadas que las respuestas a los modelos de ondas sinusoidales producidas electrónicamente.

El maestro se movía en un ámbito amplio, pero su emisión no era libre y su timbre no estaba limpio, por lo que ofrecía una voz rota al hablar y al cantar. Su sonido tenía esa rasposidad particular que le situaba dentro de un estilo de emisión característico de algunos cantantes de música ligera o de jazz. En el proceso de búsqueda de un estilo personal de canto, la atracción hacia determinados modelos vocales por afinidad estética jugó un papel relevante que le había llevado a adoptar por mímesis y a hacer suyas y reivindicar determinadas formas de emisión, sin cuestionarse en modo alguno la conveniencia de ello, ni las posibles consecuencias sobre su salud vocal. Como varón, no tomaba en cuenta que su emisión podía perturbar y confundir a los más pequeños e inexpertos ya que no emitía en la misma frecuencia que los niños sino una octava más grave y, cuando esto ocurría, lo constataba, pero no le daba importancia con tal de que cantasen, y no 
tomaba medidas para evitarlo. La falta de conciencia sobre las implicaciones didácticas del modelo vocal en la escuela le llevaba, además, a mostrar a los alumnos modelos vocales grabados de dudosa idoneidad en la mayoría de las ocasiones e incluso, puntualmente, a dirigirse a los niños y a hacerles preguntas por encima de una grabación que sonaba muy fuerte, ofreciendo un modelo de voz hablada gritado y estridente, lo que, por otro lado, añadía un factor de riesgo más sobre su propia salud vocal.

\section{CONCLUSIONES Y SUGERENCIAS}

El análisis y la interpretación de los datos revelan que el perfil del maestro resultaba determinante a la hora de comprender su práctica docente y que tenía una enorme incidencia en la práctica vocal de aula. Su estilo didáctico, lejos de ser innovador, se había dejado llevar sin fisuras por un texto que propiciaba determinadas dinámicas y estrategias en menoscabo de otras, que caía en la rutina de las fichas y potenciaba el conocimiento declarativo en detrimento del procedimental. No obstante, el maestro promovía proyectos educativos que daban cauce a la creatividad y al trabajo cooperativo entusiasmando a los niños. Gracias a su impronta, su entrega y su carisma, conseguía que sus alumnos tuviesen una actitud proclive hacia la música y, sobre todo, que disfrutasen.

El rasgo que definía por antonomasia la naturaleza del canto que se practicaba en el aula era que resultaba desnaturalizado debido a que se circunscribía a cantar canciones y servía únicamente como recurso para algunos aprendizajes musicales, fundamentalmente la lectura. El maestro no contemplaba la instrucción vocal como un requisito indispensable para el adecuado progreso en el ejercicio del canto y no llevaba a cabo práctica alguna para mejorar el proceso de coordinación en la producción vocal, olvidando que este proceso psicomotor tan complejo no sucede en la mayoría de los niños de forma espontánea, y que éstos necesitan, tal como sugiere PHILLIPS (1996), un trabajo específico que lo articule en relación con todos y cada uno de los parámetros que le son propios. De ahí que no ponía en práctica estrategias para enseñar una postura adecuada y una respiración, emisión, articulación y dicción correctas, como recomiendan PHILLIPS y AITCHISON (1997). Hacía, en cambio, algún requerimiento puntual a los alumnos por medio de determinadas imágenes, pero sin proporcionar las estrategias adecuadas para conseguir el objetivo que pretendía, lo que reflejaba, además, la ausencia de una experiencia vicaria en canto por parte del maestro. Este tipo de requerimientos podían perturbar y confundir a los alumnos porque, con frecuencia, les llegaban a través de una terminología canora equívoca, confusa y, a veces, substancialmente errónea, además de que el uso de imágenes inadecuadas para el nivel de madurez de los alumnos, en tanto que niños, tampoco ayudaba.

Aunque el maestro cantaba un ámbito amplio, el modelo vocal que ofrecía en el aula se caracterizaba por la falta de libertad en la emisión y por un sonido duro y directamente apoyado en la garganta, producto de la tensión a la hora de emitir y de la falta de utilización de los resonadores. Su timbre no estaba limpio, lo que originaba una voz rota al hablar y al cantar. Por todo ello, la calidad de su emisión resultaba afectada. El maestro identificaba algunas de las cualidades acústicas de su propio timbre tales como esa rasposidad en la emisión que le caracterizaba, por lo que la valoración subjetiva que hacía de ello se correspondía con la perceptual o psicoacústica de la investigación. No tomaba en cuenta que, como varón, su emisión podía perturbar y confundir a los más pequeños y/o inexpertos. Cuando esto ocurría, lo constataba, pero no le daba importancia con tal de que cantasen y no tomaba medidas tales como cultivar la ligereza en la emisión, cuando menos, o utilizar la voz de falsete con el fin de ofrecer un modelo vocal en la octava de los niños. No utilizaba estrategia alguna cuando los niños, sin distinción de curso, nivel o género, cantaban sistemáticamente en octava grave, dándose el caso de evidencias fehacientes en las réplicas de los niños cuando respondían por imitación al modelo vocal que les proponía cantando a cappella. El 
maestro, no sólo manifestaba la ausencia de dudas respecto de su propia emisión, sino que, en ocasiones, presentaba a los alumnos modelos vocales grabados de dudosa conveniencia.

La falta de conciencia en cuanto a las implicaciones didácticas del modelo vocal -entendido éste como un parámetro que afecta a la percepción tonal y, por lo tanto, a la afinación y a la calidad vocal, dada la relación que existe entre percepción y producción de los sonidos, según PHILLIPS 1996) - generaba una problemática vocal específica y relevante en su calidad de docente de educación primaria y en tanto que varón. El maestro no era consciente de las consecuencias de asociaciones kinestésicas erróneas provocadas por una emisión incorrecta o por el hecho de cantar en un registro demasiado grave, hechos ambos que van configurando una conciencia propioceptiva inapropiada respecto al canto de los niños, lo que resulta inconveniente para el aprendizaje del canto y perjudicial para la salud vocal de los alumnos.

El proceso de construcción de la identidad vocal del docente emergía en toda su complejidad, y confluían en él diversos parámetros entre los que cabría destacar que: su formación vocal había sido reglada, aunque exigua y puntual; diferentes episodios a propósito de prácticas vocales docentes recibidas en la juventud fueron cruciales y le habían llevado a inhibirse de continuar formándose en esa línea; sus experiencias vocales más significativas provenían de contextos didácticos alternativos; su práctica vocal era continuada, principalmente como solista dentro de la música ligera, incluyendo gran variedad de estilos, aunque no había participado en otras experiencias vocales ya fuesen profesionales o amateurs. De todo ello se derivaba una autoconciencia vocal cuando menos sesgada - si no deformada o subvertida- ya que, siendo un profesional de la voz, no tenía conciencia de sus problemas y necesidades vocales y no había hecho de la formación vocal el eje de su formación continua como docente. Por otra parte, ante determinados indicios de falta de salud vocal, que detectaba e identificaba con precisión, y que debido a la atracción y mimetización de ciertos patrones estéticos le habían configurado, no sólo no contemplaba la posibilidad de solventarlos solicitando apoyo profesional, sino que les otorgaba el rango de categoría estética.

La diversidad de la problemática vocal emergente a propósito del canto de los niños, ponía de manifiesto las interacciones entre la formación vocal del maestro, el modelo vocal que ofrecía y la práctica de aula. Esta problemática se concretaba en una variedad de respuestas entre los alumnos que desafinaban y los que no cantaban, pasando por fluctuaciones de diversa índole, cambios de tonalidad, ronroneos, extrañas heterofonías, o la persistencia de cantar en octava grave. Cantar sólo en el registro grave produce una calidad áspera que puede dañar las cuerdas vocales (PHILLIPS 1996). Muy pocas veces los niños cantaban afinados y en su octava. El maestro no detectaba la problemática vocal de sus alumnos. Detectaba y categorizaba sólo una mínima parte y, cuando esto ocurría, no ofrecía estrategia alguna que pudiera remediar el problema o no le daba importancia.

El uso exclusivo y sin ningún tipo de filtro del repertorio que proponía el libro de texto incrementaba las dificultades a la hora de cantar, independientemente del curso, el nivel, o el género. La mayor parte de este repertorio distaba de ser idóneo para la etapa en cuanto al ámbito, la dificultad de la interválica, la extensión excesiva de las canciones o la falta de adecuación de las melodías y textos versionados sobre repertorio que formaba parte del corpus de canciones colectivo, y que seguía vigente en la memoria de los niños.

En cuanto al género, no se encontraban diferencias significativas. Las chicas cantaban a veces con más entusiasmo, pero en otras ocasiones con timidez. Puntualmente, cantaban más afinadas y en su octava, pero en líneas generales participaban de la misma problemática vocal que sus compañeros varones.

Entre el pensamiento y las acciones del maestro existían correspondencias, pero también contradicciones significativas. La identificación de las inconsistencias y contradicciones subyacentes a las concepciones y acciones de los profesores de música dentro de la enseñanza general y cómo éstas configuran la práctica musical, contribuyen a profundizar en el conocimiento y en la comprensión de algunas derivaciones involucradas en esas prácticas, así como a señalizar determinados problemas y los posibles caminos para resolverlos (DEL BEN y HENTSCHKE, 2002). 
El pensamiento de Aitor se correspondía con sus actuaciones docentes en cuanto que asumía el rol de maestro como educador y no como mero transmisor de conocimientos. Era consecuente con su pensamiento social, estableciendo en términos generales líneas prioritarias de actuación docente en cuanto a compromiso, entusiasmo, entrega y dedicación, desarrollando un estilo y una impronta muy personales. La práctica docente, en cambio, mostraba la contradicción entre el profesor carismático y dinámico que quería cambiar la educación, que desarrollaba, de hecho, proyectos que encandilaban a los niños y daban cauce a la creatividad o al trabajo cooperativo, y el que seguía la rutina de las fichas o los controles del libro. El maestro era consciente de algunas de las carencias de su formación en general y de su formación musical en particular pero, aun así, la formación continua como docente no formaba parte de sus vivencias ni de sus expectativas. Había una contradicción en el discurso del maestro puesto que el canto era un tema omnipresente aunque no desde el punto de vista del didacta sino a propósito de sí mismo, mientras que el canto de los alumnos no formaba parte de su discurso. Existían contradicciones entre el profesional de la voz y el maestro que consideraba su modelo vocal como un valor, como una cualidad tímbrica sin consecuencias en la docencia, entre el maestro que era meticuloso cuando corregía la voz hablada en la dicción, la articulación, el fraseo, la intensidad o la ductilidad para recrear un personaje, pero no contemplaba la instrucción vocal de sus alumnos.

Durante su etapa de formación coexistieron dos vías que discurrían paralelamente, por un lado la vía de la formación convencional y, por otro, la de la formación musical, entre las cuales se producía una alternancia sucesiva. De esta situación derivaba un dilema, ya que en algunos momentos se veía obligado a dar prioridad a una vía en detrimento de la otra. El dilema que vivía el joven que se estaba formando no desapareció al comenzar la vida profesional, muy al contrario, se acrecentó, haciéndose más profundo. Esas alternancias se reproducían también entre el docente y el profesional de la música. Sus circunstancias personales y vitales -ausencia de un entorno cultural y económico propicios- teñidas de cierto determinismo y una imagen lábil de sí mismo no le permitían contemplar esta dualidad como una opción con facetas complementarias, aunque de facto lo fuesen, sino como opciones excluyentes que había alternado por imperativos de supervivencia económica. De la génesis y posterior gestión de estas alternancias y vivencias duales, emergía un conflicto aún no resuelto que teñía su discurso de cierta frustración e indudable escepticismo y pesadumbre, donde la dicotomía entre el profesional de la música y el docente adquiría profundos y variados significados.

De este estudio se derivan sugerencias significativas para la formación del profesorado relacionadas con la necesidad la naturaleza y la dirección de la formación vocal de los maestros. En lo profundo del caso late con fuerza la problemática de la educación musical en España, cuyo sistema para Aitor había resultado arduo y falto de sentido, habiendo tenido que buscar vías alternativas para dar cauce a su necesidad de crecer como músico y, por encima de todo, a su necesidad de hacer música. La salud vocal de los maestros ha llegado a convertirse en un problema de salud pública (EsCALONA, 2006). La mayoría de los desórdenes vocales en profesores están asociados a factores ocupacionales (PICCOLOTTO et al., 2010) y el uso vocal inapropiado, entre otros, se relaciona con determinados síntomas vocales en profesores de primaria y secundaria. La prevención básica de los desórdenes vocales en los maestros podría solventarse con programas de educación vocal para ayudar a detectar, tratar y reducir dichos posibles desórdenes vocales (Bovo et al., 2007). En el caso del maestro de música en tanto que usuario de la voz profesional confluyen la voz hablada y el canto. Cabe plantearse la conveniencia de tipificar la manera en que esa formación técnico-vocal debe producirse en su especificidad una vez que se haya delimitado el papel del maestro de música en este campo dentro de las aulas de primaria, a la vez que definir y sistematizar cuál es el modelo adecuado de voz cantada que deberá ofrecer en el aula: un modelo vocal específico que se adapte a las características vocales de los niños cuyas voces según PHILLIPS (1996), ni son ni deben ser tratadas como las voces maduras. Todo ello con el fin de que, como maestro, pueda adquirir de un sólido marco de referencia que le haga comprender que la trascendencia de la formación vocal radica en tres aspectos interrelacionados: su propia salud vocal, 
las implicaciones pedagógicas de su emisión tanto hablada como cantada y la formación de sus alumnos.

\section{Referencias}

Behlau, M.; Oliveira, G. (2009): "Vocal hygiene for the voice professional". Current Opinion in Otolaryngology \& Head and Neck Surgery, 17, 149-154.

Bovo, R.; Galceran, M.; Petruccelli, J.; Hatzopoulos, S. (2007): "Vocal problems among teachers: Evaluation of a preventive voice program". Journal of Voice, 12(6), 705-722.

BRESLER, L. (2004): "Metodología de investigación cualitativa: Prestando atención a la música escolar como género en sus micro y macro contextos". Revista Electrónica Complutense de Investigación en Educación Musical, 1(1). Consultado en www.ucm.es/info/reciem el 14/1/2007.

CAsado, J. C.; PÉRez, A. (2009): Trastornos de la voz: Del diagnóstico al tratamiento. Málaga, Aljibe.

Chen, S. H.; Chiang, S. C.; Chung, Y. M.; Hsiao, L. C.; HsiaO, T.Y. (2010): "Risk factors and effects of voice problems for teachers". Journal of Voice, 24(2), 183-192.

Coffey, A.; AtKinson, P. (2005): Encontrar el sentido a los datos cualitativos: Estrategias complementarias de investigación. Alicante, Publicaciones de la Universidad de Alicante.

Corbin, J.; STRAuSS, A. (1990): "Grounded theory research: Procedures, canons, and evaluative criteria”. Qualitative Sociology, 13(1), 3-21.

Del Ben, L.; HeNTSCHKE, L. (2002): "Educação musical escolar: Uma investigação a partir das concepções e ações de três professoras de música". Revista Electrónica de LEEME (Lista Electrónica Europea de Música en la Educación, 10. Consultado en http://musica.rediris.es/leeme/revista/hentschke.htm el 7/2/2007.

EISNER, E. W; (1998): El ojo ilustrado: Indagación cualitativa y mejora de la práctica educativa. Barcelona, Paidós.

EsCALONA, E. (2006): "Prevalencia de síntomas de alteraciones de la voz y condiciones de trabajo en docentes de escuela primaria Aragua-Venezuela". Salud de los Trabajadores, 14(2), 3153.

GreEN, G. A. (1990): “The effect of vocal modeling on pitch-matching accuracy of elementary schoolchildren". Journal of Research in Music Education, 38(3), 225-231.

HiRAnO, M. (1981): Clinical examination of voice. New York, Springer-Verlag.

KUSHNER, S. (2002): Personalizar la evaluación. Madrid, Morata.

Lincoln, Y.S.; GuBA, E.G. (1985): Naturalistic inquiry. Beverly Hills (California), Sage.

Mauduit, B. (2005). "Figurativité et pédagogie du chant". Recherche en Éducation Musicale, 23, $1-17$.

PESHKIN, A. (2000): “The nature of interpretation in qualitative research". Educational Researcher, 29(9), 5-9.

PHILLIPS, K. H. (1992): "Research on the teaching of singing”. En R. Colwell (ed.): Handbook of Research on Music Teaching and Learning (págs. 568-576). New York, Schirmer.

PhILliPS, K.; AITCHISON, R. (1997): "Effects of psychomotor instruction on elementary general music students' singing performance". Journal of Research in Music Education, 45(29), 185-196.

PhILLIPS, K. H. (1996): Teaching kids to sing. Nueva York, Schirmer.

Piccolotto, L.; Dias de Oliveira, M. R.; Pimentel, S.; De Assis, A. C.; de Fraga, D.; EGERLAND, E.; FIGUEIRA, S. (2010): "Influence of abusive vocal habits, hydration, mastication, and sleep in the occurrence of vocal symptoms in teachers". Journal of Voice, 24(1), 86-92.

Price, H. E.; Yarbrough, C.; Jones, M.; Moore, R. S. (1994): "Effects of male timbre, falsetto, and sine-wave models on interval matching by inaccurate singers". Journal of Research in Music Education, 42(4), 269-284. 
RusineK, G. (2004): “Aprendizaje musical significativo”. Revista Electrónica Complutense de Investigación en Educación Musical, 1(5). Consultado en www.ucm.es/info/reciem el 3/11/2005.

Russell, A.; OAtes, J.; GreenwoOK, K. M. (1998): "Prevalence of voice problems in teachers". Journal of Voice, 12, 467-479.

SALDAÑA, J. (2009): The coding manual for qualitative researchers. Thousand Oaks (California): Sage.

SivASANKAR, M.; LEYDON, C. (2010): "The role of hydration in vocal fold physiology". Current Opinion in Otolaryngology \& Head and Neck Surgery, 18(3), 171-175.

STAKE, R. (1998): Investigación con estudio de casos. Madrid, Morata.

Welch, G. F.; Himónides, E.; HowARD, D.; BRERETON, J. (2006): “Un proyecto de investigaciónacción innovador usando una nueva tecnología de respuesta vocal en tiempo real en el aula de canto". Eufonía. Didáctica de la Música, 38, 56-72.

YARbrough, C.; GreEn, G.; Benson, W.; Bowers, J. (1991): "Inaccurate singers: An exploratory study of variables affecting pitch-matching". Bulletin of the Council for Research in Music Education, 107, 23-24.

YARBrough, C.; Bowers, J.; Benson, W. (1992): "The effect of vibrato on the pitch-matching accuracy of certain and uncertain singers". Journal of Research in Music Education, 40(1), 30-38. 